\title{
Genetic Components of Days Open Under Heat Stress
}

\author{
S. Oseni, I. Misztal, S. Tsuruta, and R. Rekaya \\ Department of Animal and Dairy Science, \\ The University of Georgia, Athens 30602-2771
}

\section{ABSTRACT}

A reaction norm approach was used to estimate the genetic parameters of days open (DO) with a model that accounted for heat stress. Data included DO records for Georgia, Tennessee, and North Carolina in the Southeastern United States. A fixed effect model included herd-year, month of calving (MOC), age of cow, and a regression on 305-d milk yield. The reaction norm model additionally included the effect of animal with random regression on a heat stress index (HI), calculated as the standardized solutions to MOC derived from the fixed effect model; the residual variance was assumed to be a function of the HI. The shape of the distribution of the HI was close to a sinusoidal function with the highest value in March/April and the lowest value in September. Genetic and residual variances and heritabilities were highest for spring calvings and lowest for fall calvings. The variance associated with the random regression of the highest level of HI was 33\% of the genetic variance of the regular animal genetic effect. Genetic correlation between these effects was 0.67 . As a validation, DO data were grouped into 4 seasons of calving and treated as different traits. A 4trait mixed linear model that included the fixed effects listed above except MOC, was used to analyze the grouped data. In general, the estimates of genetic and residual variances of the multiple trait analyses followed those of the reaction norm model. Genetic correlations of spring with summer, and fall with winter were both 0.90 . Genetic correlations between spring/summer and fall/winter were around 0.80 . The reaction norm model for DO allows inexpensive genetic evaluation of fertility under heat stress. Results of such an evaluation may strongly depend on editing criteria and model specifications.

(Key words: days open, heat stress index, reaction norm, random regression model)

Abbreviation key: $\mathbf{D O}=$ days open, $\mathbf{H I}=$ heat stress index, $\mathbf{M O C}=$ month of calving, $\mathbf{N R}=$ nonreturn rate,

Received April 13, 2004.

Accepted June 10, 2004.

Corresponding author: S. Tsuruta; e-mail: shogo@uga.edu.
$\mathbf{T H I}=$ temperature-humidity index, $\mathbf{V W P}=$ voluntary waiting period.

\section{INTRODUCTION}

Current emphasis on fertility traits in dairy herds arises from deterioration in fertility levels as well as the negative economic implication of this trend on the profitability of commercial dairy herds. Fertility traits, in general, have a very high environmental component and the season (or month) of calving, in addition to the herd effect, has been identified as a major source of variation for these traits (Badinga et al., 1985; Cavestany et al., 1985; Faust et al., 1988; Ray et al., 1992; Eicker et al., 1996). Seasonal trends for fertility traits are well known. Several investigators (Thatcher et al., 1978; Seykora and McDaniel, 1983; Silva et al., 1992; Marti and Funk, 1994; VanRaden et al., 2002; Oseni et al., 2003) have reported that days open (DO) were longest for spring calvings and shortest for fall calvings in the United States. This trend was attributed to depressed fertility during the summer, when spring calvers are ready for rebreeding. High temperatures during the summer have been implicated for the reduced fertility in that season (Wolfenson et al., 2000). Although the seasonal (phenotypic) trend for DO is well established, few studies have been done to estimate genetic parameters of DO across seasons of calving (Hahn, 1969; Seykora and McDaniel, 1983; Faust et al., 1989). These authors, using paternal half-sib analyses, reported that heritability estimates for DO and firstservice conception rate were higher for spring than for fall calvings, and concluded that genetic differences in fertility levels are best observed under suboptimal (stressful) conditions.

The modeling of the genetic component of heat stress for nonreturn rate (NR) in the Southeastern United States was conducted by Ravagnolo and Misztal (2002). They estimated genetic parameters for NR using a model with a random regression on temperature-humidity index (THI). They reported that the variance of heat stress was zero at THI $=70$ but it was as large as the general additive variance at $\mathrm{THI}=84$ for NR at 90 $\mathrm{d}$, indicating that genetic variation in heat tolerance exists for NR90 d at high levels of THI among Holsteins. 
Table 1. Numbers of records and herds, and means and standard deviations of days open by state.

\begin{tabular}{lllll}
\hline State & Records & Herds & Mean & SD \\
\hline Georgia & 21,461 & 206 & 154 & 72 \\
North Carolina & 28,217 & 262 & 151 & 71 \\
Tennessee & 19,042 & 274 & 152 & 71 \\
All & 68,720 & 742 & 152 & 72 \\
\hline
\end{tabular}

The model for NR cannot be applied directly to DO because this trait is not directly associated with a particular date. The alternative is using an index based on month of calving (MOC), because such an index accounts for most of the fluctuations in DO across calving seasons. This is similar to the reaction norm model, because the stress index is implemented as solutions to MOC reparameterized to a scale of 0 (no heat stress) to 1 (maximum heat stress). The reaction norm approach is useful when phenotypes change gradually and continuously over an environmental gradient, and has been used successfully in the evaluation of animals for phenotypic plasticity (differences between phenotypes) across different environments (De Jong, 1995; De Jong and Bijma, 2002; Kolmodin et al., 2002). The objectives of this study were to analyze the genetic relationship between generic (no heat stress) and heat tolerance effects for DO and to examine changes in genetic parameters of DO by MOC using a reaction norm model.

\section{MATERIALS AND METHODS}

Fertility data on first-parity calvings of Holstein cows for Georgia, North Carolina, and Tennessee in the Southeastern United States were extracted from the AIPL/USDA database. These datasets spanned a period of $6 \mathrm{yr}$ (1997 to 2002). A summary of the datasets is shown in Table 1. In data editing, DO records less than $22 \mathrm{~d}$ were not included, and records greater than $22 \mathrm{~d}$ and less than $50 \mathrm{~d}$ were set to $50 \mathrm{~d}$. An upper limit of $250 \mathrm{~d}$ was set; records of DO greater than $250 \mathrm{~d}$ were set to $250 \mathrm{~d}$. Days open was precomputed and came with the original data file from the USDA. Details of the editing of the data, including the computation of DO are contained in VanRaden et al. (2003). Ages of cow at calving were defined using 3 -mo intervals as follows: Class 1: $\leq 23 \mathrm{mo}$; class 2: 24 to $26 \mathrm{mo}$; class 3 : 27 to 29 mo; class 4: 30 to $32 \mathrm{mo}$; class 5: 33 to $35 \mathrm{mo}$; and class 6: 36 to 38 mo. Analyses were restricted to first-parity records.

Three sets of analyses were conducted on the combined datasets for the 3 states. The first analysis fits a fixed effects model to DO to generate solutions for months of calving effect. The model used was:

$$
\begin{aligned}
y_{i j k l} & =h y_{i}+\text { moc }_{j}+\text { age }_{k} \\
& +b(\text { milk })+e_{i j k l},
\end{aligned}
$$

[model 1]

where $y_{\mathrm{ijkl}}=$ the observed DO for animal 1 in the herdyear $\left(\mathrm{hy}_{\mathrm{i}}\right)$ class $\mathrm{i}(\mathrm{i}=3073)$, calving in month $\mathrm{j}(\mathrm{j}=1$, $12)$, belonging to the age-class $\mathrm{k}(\mathrm{k}=1,6) ; \mathrm{b}($ milk $)=$ fixed regression on 305-d milk yield; and $\mathrm{e}_{\mathrm{ijk}}=$ random error associated with each observation.

Heat stress index (HI) was computed as the standardized solutions for MOC derived from model 1 using the following formula:

$\mathrm{HI}_{\mathrm{j}}=\left(\mathrm{sol}_{\mathrm{j}}-\mathrm{sol}_{\min }\right) /\left(\mathrm{sol}_{\max }-\mathrm{sol}_{\text {min }}\right)$, where $\mathrm{sol}_{\mathrm{j}}$ is the least square solution for the jth $\operatorname{MOC}(j=1,12)$; $\mathrm{sol}_{\min }$ and $\mathrm{sol}_{\max }$ are the minimum and maximum solutions for MOC, respectively.

Seasonality of calving was defined as follows:

Seasonality of calving $=$

(number of calvings in the jth MOC)/(number of calvings in the MOC with the maximum calvings).

The second analysis fits an animal model augmented by a random regression on $\mathrm{HI}$ as follows:

$$
\begin{gathered}
y_{i j k l m n}=h_{i}+\text { moc }_{j}+\text { age }_{\mathrm{k}} \\
+b(\text { milk })+a_{01}+a_{11} h_{m}+e_{i j k l m n}
\end{gathered}
$$

where $\mathrm{y}_{\mathrm{ijklmn}}=$ observed DO for animal $\mathrm{l}$ in the herdyear class $i$, calving in the month $j$, belonging to the age-class $\mathrm{k}$, and level $\mathrm{m}$ of the $\mathrm{HI} ; \mathrm{hy}_{\mathrm{i}}, \mathrm{moc}_{\mathrm{j}}$, age $\mathrm{k}_{\mathrm{k}}$, and $\mathrm{b}$ (milk) are as defined in model $1 ; \mathrm{a}_{01}$ represents the usual additive merit of cow $\mathrm{l}(\mathrm{l}=1$ to 68,720$) ; \mathrm{h}_{\mathrm{m}}$ is the $\mathrm{HI}$ function $(1 \leq \mathrm{m} \leq 12)$ and represents the explanatory variable in the reaction norm model; $a_{11}$ can be interpreted as the additive linear effect of heat tolerance of cow 1 , and $\mathrm{e}_{\mathrm{ijklmn}}=$ the random error associated with each observation. For this model, residual variances were treated as heterogeneous, using the heterogeneous residual variance option of the AIREMLF90 package (Misztal et al., 2002) as modified by Tsuruta et al., (2003).

The (co)variance structure for model 2 is:

$$
\begin{gathered}
\operatorname{Var}\left[\begin{array}{l}
\mathbf{a}_{0} \\
\mathbf{a}_{1}
\end{array}\right]=\left[\begin{array}{ll}
\mathbf{A} \sigma_{\mathrm{a} 0}^{2} & \mathbf{A} \sigma_{\mathrm{a} 0, \mathrm{a} 1} \\
\mathbf{A} \sigma_{\mathrm{a} 0, \mathrm{a} 1} & \mathbf{A} \sigma_{\mathrm{a} 1}^{2}
\end{array}\right] \\
\operatorname{Var}(\mathbf{e})=\mathbf{R}=\operatorname{diag}\left\{\mathbf{I}_{\mathrm{n} 1} \sigma_{\mathrm{e} 1}^{2} \mathbf{I}_{\mathrm{n} 2} \sigma_{\mathrm{e} 2}^{2}, \ldots \ldots . ., \mathbf{I}_{\mathrm{n} 12} \sigma_{\mathrm{e} 12}^{2}\right\}
\end{gathered}
$$

where $\mathbf{A}$ is the genetic relationship matrix among animals, and $\sigma_{\mathrm{a} 0}^{2}, \sigma_{\mathrm{a} 1}^{2}$, and $\sigma_{\mathrm{a} 0, \mathrm{a} 1}$ represent the additive genetic variances for the generic (no heat stress) and heat 
tolerance effects for DO and their covariance respectively; $\mathbf{R}$ is a diagonal matrix of heterogeneous residual effects partitioned for each MOC; $\mathrm{I}_{\mathrm{n} 1} \sigma_{\mathrm{e} 1}^{2}, \mathrm{I}_{\mathrm{n} 2} \sigma_{\mathrm{e} 2}^{2}, \ldots \ldots .$. , $\operatorname{In}_{12} \sigma_{\mathrm{e} 12}^{2}$ represent the identity matrices for the residual variances for each MOC with appropriate dimensions, and $n=$ number of records for each MOC. The heat tolerance effect determines the relative change in the fertility status of the cow for each unit increase in the HI function (Ravagnolo and Misztal, 2002).

A third analysis used data subsets based on seasons of calving as follows: Winter (December to February); spring (March to May); summer (June to August); and fall (September to November). A 4-trait model based on seasons was fit as follows:

$$
\begin{gathered}
\left.\mathrm{y}_{\mathrm{ijklt}}=\mathrm{hy}_{\mathrm{it}}+\mathrm{age}_{\mathrm{jt}}+\mathrm{b}(\text { milk }) \quad \text { [model } 3\right] \\
+\mathrm{a}_{\mathrm{kt}}+\mathrm{e}_{\mathrm{ijkl}},
\end{gathered}
$$

where $\mathrm{y}_{\mathrm{ijklt}}=$ observed $\mathrm{DO}$ on cow $\mathrm{l}$ for trait $\mathrm{t}(\mathrm{t}=1,4$ for winter, spring, summer, and fall, respectively) in the herd-year class $i$ in the age-class $j$; all other effects are as previously defined.

The (co)variance structure for model 3 is:

$$
\operatorname{Var}\left[\begin{array}{c}
\mathbf{a}_{1} \\
\mathbf{a}_{2} \\
\mathbf{a}_{3} \\
\mathbf{a}_{4}
\end{array}\right]=\left[\begin{array}{llll}
\mathbf{A} \sigma_{\mathrm{a}_{1}}^{2} & \mathbf{A} \sigma_{\mathrm{a}_{1} \mathrm{a}_{2}} & \mathbf{A} \sigma_{\mathrm{a}_{1} \mathrm{a}_{3}} & \mathbf{A} \sigma_{\mathrm{a}_{1} \mathrm{a}_{4}} \\
\mathbf{A} \sigma_{\mathrm{a}_{2} \mathrm{a}_{1}} & \mathbf{A} \sigma_{\mathrm{a}_{2}}^{2} & \mathbf{A} \sigma_{\mathrm{a}_{2} \mathrm{a}_{3}} & \mathbf{A} \sigma_{\mathrm{a}_{2} \mathrm{a}_{4}} \\
\mathbf{A} \sigma_{\mathrm{a}_{3} \mathrm{a}_{1}} & \mathbf{A} \sigma_{\mathrm{a}_{3} \mathrm{a}_{2}} & \mathbf{A} \sigma_{\mathrm{a}_{3}}^{2} & \mathbf{A} \sigma_{\mathrm{a}_{3} \mathrm{a}_{4}} \\
\mathbf{A} \sigma_{\mathrm{a}_{4} \mathrm{a}_{1}} & \mathbf{A} \sigma_{\mathrm{a}_{4} \mathrm{a}_{2}} & \mathbf{A} \sigma_{\mathrm{a}_{4} \mathrm{a}_{3}} & \mathbf{A} \sigma_{\mathrm{a}_{4}}^{2}
\end{array}\right]
$$

and

$$
\operatorname{Var}(\mathbf{e})=\mathbf{R}=\left[\begin{array}{llll}
\sigma_{\mathrm{e}_{1}}^{2} & 0 & 0 & 0 \\
0 & \sigma_{\mathrm{e}_{2}}^{2} & 0 & 0 \\
0 & 0 & \sigma_{\mathrm{e}_{3}}^{2} & 0 \\
0 & 0 & 0 & \sigma_{\mathrm{e}_{4}}^{2}
\end{array}\right],
$$

where $a_{1}, \ldots . ., a_{4}$ represent the additive genetic merit of the animal in winter, spring, summer, and fall, respectively, $\mathbf{A}$ is the genetic relationship matrix among animals; and $\sigma_{\mathrm{a} 1}^{2}, \ldots . ., \sigma_{\mathrm{a} 4}^{2}$ and $\sigma_{\mathrm{a} 1, \mathrm{a} 2}, \ldots \ldots, \sigma_{\mathrm{a} 1, \mathrm{a} 4}$ represent the additive genetic (co)variances for DO in the different seasons of calving. For all the models, (co)variance components were estimated using the Average Information REML procedures via AIREMLF90 (Misztal et al., 2002).

\section{RESULTS AND DISCUSSION}

Figure 1 shows the plot of least square means of DO by month of calving. Days open were longest for March/

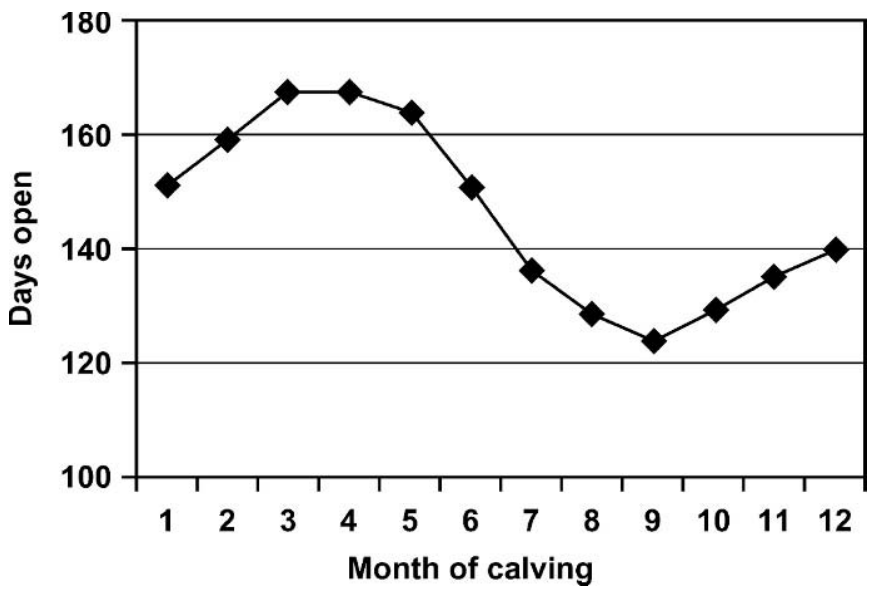

Figure 1. Least square means of days open across months of calving using combined data from 3 states.

April (spring) calvings, and shortest for September (fall) calvings, in agreement with reports in the literature (Gwazdauskas, 1985; Marti and Funk, 1994). Spring calvings are associated with prolonged DO for the following reasons-intentional delay by the farmer due to poor conception in the summer period when spring calvers are being rebred, or lengthened voluntary waiting period (VWP) (Badinga et al., 1985; Cavestany et al., 1985; Eicker et al., 1996). Differences between seasons are also shown by the distribution of records across calving seasons (Figure 2). For fall, winter, and summer calving DO records, highest frequencies were at 70, 80, and $100 \mathrm{~d}$ postcalving, respectively. Furthermore, the rate of decline differs for the 3 seasons. It was steep for winter calvings and slow for summer, and fall re-

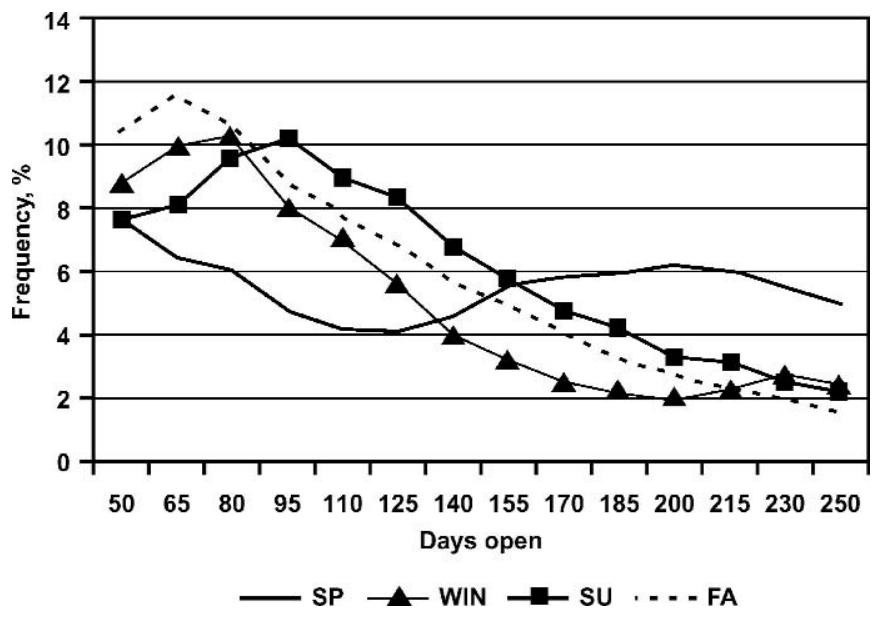

Figure 2. Frequency distribution for days open up to $250 \mathrm{~d}$ by season of calving for combined data from 3 states $(\mathrm{SP}=$ spring, WIN = winter, $\mathrm{SU}=$ summer, and $\mathrm{FA}=$ fall calvings). 


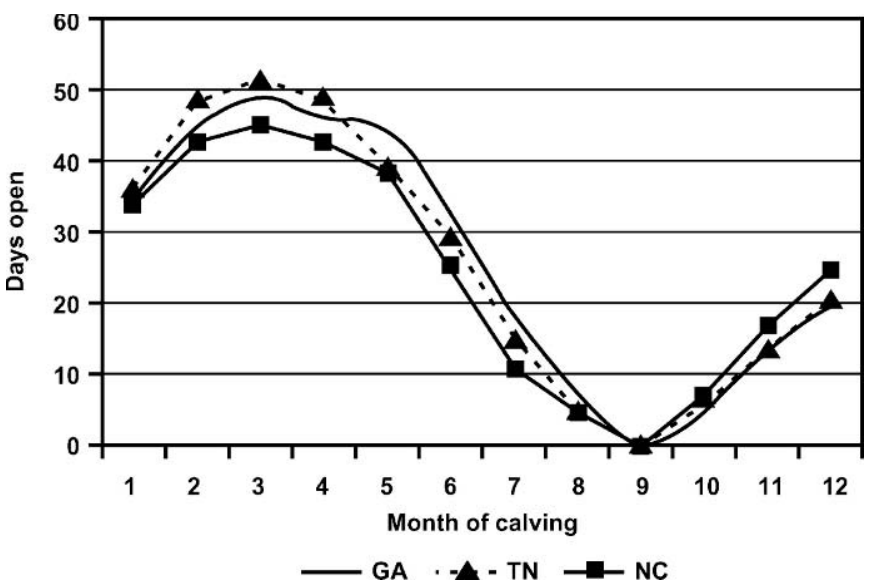

Figure 3. Least square means for days open as deviations from September calving means for Georgia (GA), Tennessee (TN), and North Carolina (NC).

cords were intermediate. In sharp contrast, spring calving records had double peaks at 65 and $215 \mathrm{~d}$, corresponding to the peaks for cows conceiving pre- and postsummer, respectively. Oseni et al. (2003) have shown that spring MOC have a bimodal distribution for DO, due perhaps, to prolonged VWP, intentional delay, or poor fertility in the summer, when winter and spring calvers are being rebred.

Figure 3 shows the least square means of DO for each MOC as deviations from September calvings. The range of DO across all MOC was $50 \mathrm{~d}$, implying that, on average, cows calving in March remain open $50 \mathrm{~d}$ longer than those calving in September, for these 3 states. The grouping of MOC into seasons of calvings (Table 2) shows that spring calvings recorded longest DO, followed by winter calvings, whereas summer and fall had the shortest DO intervals. Marti and Funk (1994) reported similar findings. Results also indicate that, on average, cows calving in spring were open for about 36 $\mathrm{d}$ longer than those calving in the fall. Ray et al. (1992) reported a range of $28 \mathrm{~d}$ for spring calvers in Arizona, and Seykora and McDaniel (1983) reported that spring calvings were open $17 \mathrm{~d}$ longer than fall calvings in

Table 2. Number of records, least square means, standard deviations, and mean deviations ${ }^{1}$ of days open across calving seasons.

\begin{tabular}{lllll}
\hline Season & Records & Means & SD & $\begin{array}{l}\text { Deviations } \\
\text { from fall }^{1}\end{array}$ \\
\hline Winter & 17,539 & 150 & 77 & 20 \\
Spring & 15,783 & 166 & 70 & 36 \\
Summer & 16,199 & 139 & 65 & 9 \\
Fall & 19,199 & 130 & 70 & 0 \\
All & 68,720 & 152 & 72 & 22 \\
\hline
\end{tabular}

${ }^{1}$ Fall calvings used as a baseline.

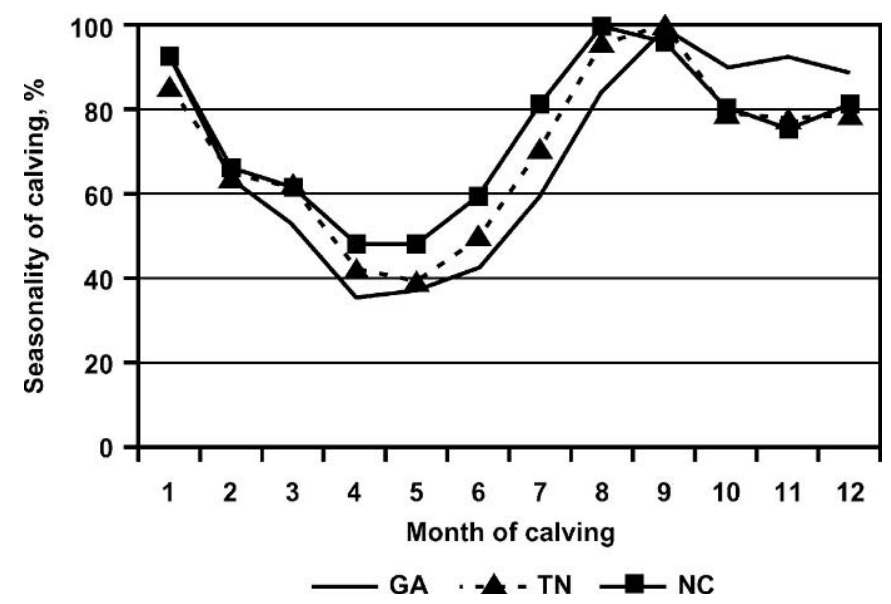

Figure 4. Seasonality of calving for Georgia (GA), Tennessee (TN), and North Carolina (NC).

North Carolina herds. Disparities in literature reports are expected due to time trends; for example, Washburn et al. (2002) have shown that mean DO changed drastically over time from $125 \mathrm{~d}$ in 1983 to $170 \mathrm{~d}$ in 1999 for states in the Southeastern United States.

The seasonality of calving defined approximately as the number of calvings in the jth MOC as a proportion of the number of calvings in the fall (Figure 4) also showed seasonal trends. The highest number of calvings occurred in September (corresponding to successful December/January or winter matings), whereas the lowest number of calvings was in May (corresponding to successful July/August or summer matings of the previous year). High THI in the summer in the Southeastern United States and its effects on fertility and pregnancy rates may explain the disparities between seasons in the frequencies of calvings (Wolfenson et al., 2000).

The HI function is shown in Figure 5. This function has a range of 0 (no heat stress, or best MOC) to 1 (highest level of heat stress, worst MOC). This function was calculated using the least square means of DO for each MOC and it represents the explanatory variable in the reaction norm model (model 2). Despite the fact that some information in the dependent variable (DO) is included in the explanatory variable HI, this model has been successfully applied in several studies on phenotypic plasticity across different environments (De Jong, 1995; De Jong and Bijma, 2002; Kolmodin et al., 2002). With respect to fertility, an advantage in this approach is the fact that calving seasons (or the environment) can be categorized as synergistic, antagonistic, or nil in the expression of the trait DO, because of differences in the level of heat stress between seasons. Also, because of differences in the level of seasonal heat 


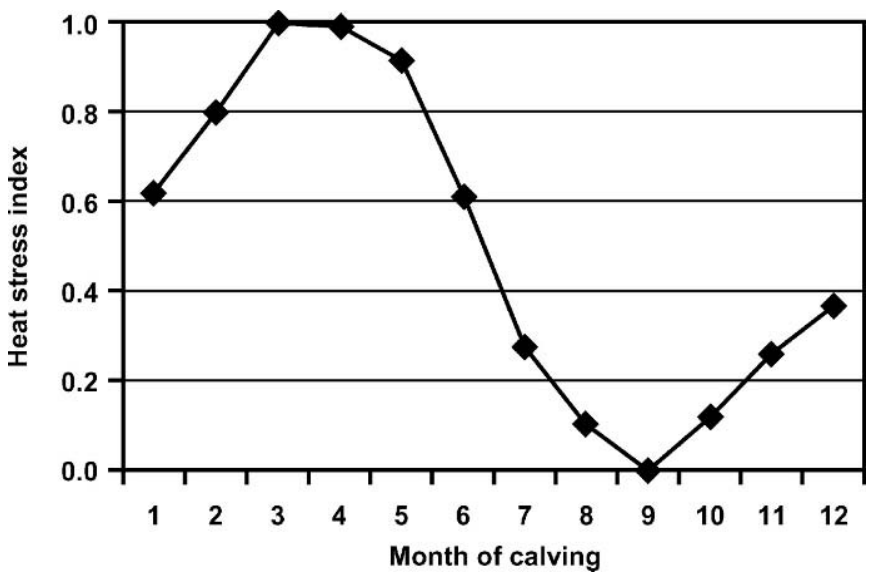

Figure 5. Heat stress index based on the least square means for days open across months of calving using combined datasets for 3 states.

stress between regions, the HI function is expected to vary between regions in the United States.

Figures 6 to 8 show the residual and additive genetic variances and heritability estimates derived from the random regression model (model 2) and multiple-trait model (model 3). Both models showed seasonal fluctuations in all 3 parameters of interest. Estimates for model 3 showed greater spread in variances and heritabilities. The highest genetic variance from model 2 was for March/April calvings and the lowest estimates were for fall (September) calvings, whereas model 3 estimates for genetic variance showed a steady decline from winter through spring and summer, with lowest estimates in the fall calving season. Variances in the random regression model (model 2) are restricted by the shape of the HI function, although the restrictions could

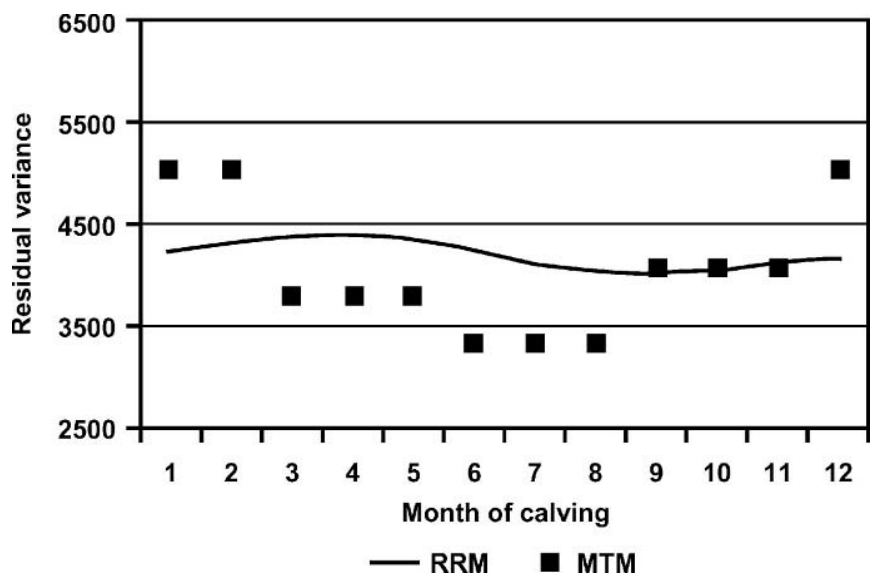

Figure 6. Estimated residual variances from random regression model (RRM, model 2) and multiple trait model (MTM, model 3) across calving seasons using combined datasets for 3 states.

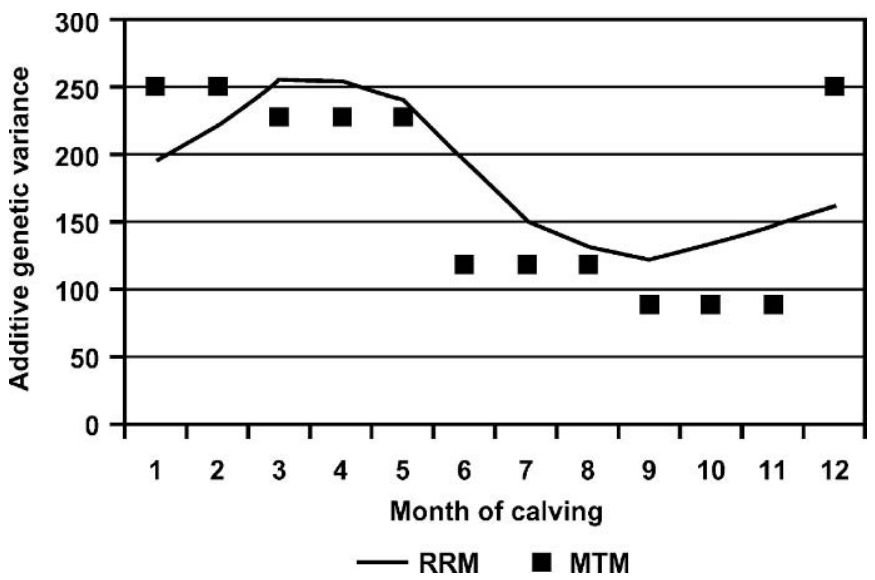

Figure 7. Estimated additive genetic variances from random regression model (RRM, model 2) and multiple trait model (MTM, model 3 ) across calving seasons using combined datasets for 3 states.

be lowered if the model was extended to second-order regressions, for example. On the other hand, variances in the multiple-trait model (model 3) cannot change within traits. This model has many more parameters resulting in larger sampling variances. The genetic correlation between the regular and heat stress effects from model 2 was 0.67 . The correlations between seasons (from model 3) ranged from 0.78 to 0.90 (Table 3 ). These correlations indicate that the ranking of animals showed small changes across different calving seasons. This contradicts the results of Ravagnolo and Misztal (2002) for NR at $90 \mathrm{~d}$, where the correlations were negative. In an unpublished study, we used the same model for pregnancy rate, a trait that places higher emphasis on lower DO. In that study, the correlations were nega-

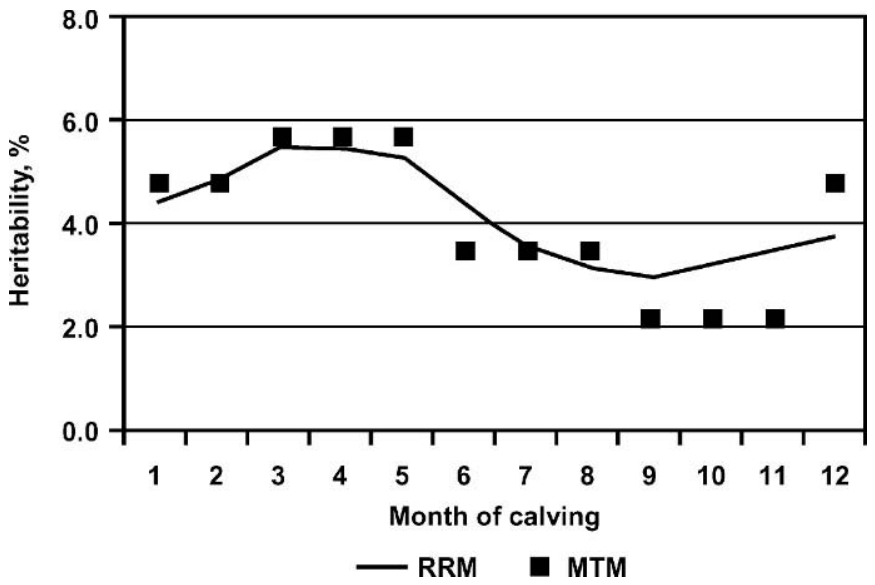

Figure 8. Heritability estimates from random regression model (RRM, model 2) and multiple trait model (MTM, model 3) across calving seasons using combined datasets for 3 states. 
Table 3. Genetic correlations between days open in different seasons. ${ }^{1}$

\begin{tabular}{llll}
\hline Season & Spring & Summer & Fall \\
\hline Winter & 0.84 & 0.82 & 0.90 \\
Spring & & 0.90 & 0.83 \\
Summer & & & 0.78 \\
\hline
\end{tabular}

${ }^{1}$ Seasons were defined as follows: Winter = December-February; Spring $=$ March-May; Summer $=$ June-August; Fall $=$ September November.

tive. One possibility is that the analyses with $\mathrm{DO}$ were influenced by management interventions that resulted in large DO. Such interventions could be intentional delay in breeding, especially for high-producing cows, or different applications of synchronization of estrus/ ovulation protocols during different seasons. The seeming contradiction with NR and pregnancy rate results may reflect the problems associated with the calculations of these 2 variables in different seasons. Pregnancy rate, for example, assumes a standard VWP, which may not be the practice at all for breedings in spring and fall in herds in Georgia, Tennessee, and North Carolina. Nonreturn rate assumes that cows are rebred continuously; in reality, cows may be rebred twice for spring calvings before the farmer stops for the summer, whereas he would continue to rebreed fall freshening cows until they become pregnant.

Seasonal difference in genetic variations for DO is shown from the results of both models. This is further validated by the estimates for heritability (Figure 8). Both models show similar estimates for heritabilities across calving seasons. Heritability estimates were highest for spring calvings $(6 \%)$ and lowest for fall (2 to $3 \%$ ). These estimates indicate that the seasonal fluctuations in DO have some genetic component, with the implication that sires could be selected for lower seasonal DO. These results agree with previous studies (Seykora and McDaniel, 1983; Faust et al., 1989). Seykora and McDaniel (1983) reported heritability estimates of 9 and 5\% for spring and fall calvings, respectively, supporting the argument that environmental stress enhances the expression of genetic variability. A similar conclusion was drawn by Faust et al. (1989), who reported that heritability estimates from paternal half-sib analysis for first-service conception rate for warm season were $2 \times$ higher than estimates for cooler seasons. These authors also noted that sires changed ranks more often than predicted by inheritance and suggested a sire $\times$ season interaction for first-service conception rate.

The usefulness of DO for heat stress studies is limited without additional comprehensive information on precise mating dates, length of VWP, persistency of mat- ing, preferential husbandry, and reproductive protocols (e.g., synchronization of estrus, timed AI). Prolonged DO under heat stress could have occurred for many reasons and these were neither available nor accounted for in this study. Thus, highly productive cows may have artificially low evaluations under heat stress.

\section{CONCLUSIONS}

The reaction norm model allows inexpensive genetic evaluation for DO under heat stress, because it does not require the collection and analysis of weather information or detailed fertility data. However, its usefulness is, in large part, conditioned by the availability and quality of the recorded fertility data. Seasonal fluctuations in DO have a genetic component; therefore, selection of sires for lower seasonal DO may be possible.

\section{ACKNOWLEDGMENTS}

The meticulous efforts of the 2 anonymous reviewers are greatly appreciated.

\section{REFERENCES}

Badinga, L., R. J. Collier, W. W. Thatcher, and C. J. Wilcox. 1985. Effects of climate and management factors on conception rate of dairy cattle in subtropical environment. J. Dairy Sci. 68:78-85.

Cavestany, D., A. B. el-Wishy, and R. H. Foote. 1985. Effect of season and high environmental temperature on fertility of Holstein cattle. J. Dairy Sci. 68:1471-1478.

De Jong, G. 1995. Phenotypic plasticity as a product of selection in a variable environment. Am. Nat. 145:493-512.

De Jong, G., and P. Bijma. 2002. Selection and phenotypic plasticity in evolutionary biology and animal breeding. Livest. Prod. Sci. 78:195-214.

Eicker, S. W., Y. T. Gröhn, and J. A. Hertl. 1996. The association between cumulative milk yield, days open, and days to first breeding in New York Holstein cows. J. Dairy Sci. 79:235-241.

Faust, M. A., B. T. McDaniel, and O. W. Robinson. 1989. Genetics of reproduction in primiparous Holsteins. J. Dairy Sci. 72:194-201.

Faust, M. A., B. T. McDaniel, O. W. Robinson, and J. H. Britt. 1988. Environmental and yield effects on reproduction in primiparous Holsteins. J. Dairy Sci. 71:3092-3099.

Gwazdauskas, F. C. 1985. Effect of climate on reproduction in cattle. J. Dairy Sci. 68:1568-1578.

Hahn, J. 1969. Inheritance of fertility in cattle inseminated artificially. J. Dairy Sci. 52:240-244.

Kolmodin, R., E. Strandberg, P. Madsen, J. Jensen, and H. Jorjani. 2002. Genotype by environment interaction in Nordic dairy cattle studied using reaction norms. Acta Agric. Scand. 52:11-24.

Marti, C. F., and D. A. Funk. 1994. Relationship between production and days open at different levels of herd production. J. Dairy Sci. 77:1682-1690.

Misztal, I., S. Tsuruta, T. Strable, B. Auvray, T. Druet, and D. Lee. 2002. BLUPF90 and related programs (BGF90). CD-ROM Communication 28:07 in Proc. 7th World Congr. on Genetics Applied to Livestock Production, Montpellier, France.

Oseni, S., I. Misztal, S. Tsuruta, and R. Rekaya. 2003. Seasonality of days open in US Holstein. J. Dairy Sci. 86:3718-3725.

Ravagnolo, O., and I. Misztal. 2002. Effect of heat stress on nonreturn rate in Holstein cows: Genetic analyses. J. Dairy Sci. 85:30923100 .

Ray, D. E., A. H. Jassim, D. V. Armstrong, F. Wiersma, and J. D. Schuh. 1992. Influence of season and microclimate on fertility of 
dairy cows in a hot-arid environment. Int. J. Biometeorol. $36: 141-145$

Seykora, A. J., and B. T. McDaniel. 1983. Heritabilities and correlations of lactation yields and fertility for Holsteins. J. Dairy Sci. 66:1486-1493.

Silva, H. M., C. J. Wilcox, W. W. Thatcher, R. B. Becker, and D. Morse. 1992. Factors affecting days open, gestation length, and calving interval in Florida dairy cattle. J. Dairy Sci. 75:288-293.

Thatcher, W. W., H. Roman-Ponce, and D. E. Buffington. 1978. Environmental effects on animal performance. Page 219 in Large Dairy Herd Management. C. J. Wilcox, ed. Univ. Florida Press, Gainesville, FL.

Tsuruta, S., I. Misztal, and T. Druet. 2003. Comparison of estimation methods for heterogeneous residual variances with random regression models. J. Dairy Sci. 86(Suppl. 1):113. (Abstr.)
VanRaden, P. M., A. Sanders, M. Tooker, R. Miller, and D. Norman. 2002. Daughter pregnancy rate evaluation of cow fertility. AIPL Presentation. http://aipl.arsusda.gov/reference/fertility/DPR_ rpt.htm. Accessed Jan. 22, 2004.

VanRaden, P. M., M. E. Tooker, A. H. Sanders, and G. R. Wiggans. 2003. Quality of data included in genetic evaluations for daughter pregnancy rate. J. Dairy Sci. 86(Suppl. 1):132.(Abstr.)

Washburn, S. P., W. J. Silva, C. H. Brown, B. T. McDaniel, and A. J. McAllister. 2002. Trends in reproductive performance in Southeastern Holstein and Jersey DHI Herds. J. Dairy Sci. 85:244-251.

Wolfenson, D., Z. Roth, and R. Meidan. 2000. Impaired reproduction in heat-stressed cattle: Basic and applied aspects. Anim. Reprod. Sci. 60-61:535-547. 